\title{
Application of the generic process modelling in the preservation of heritage school buildings
}

\author{
Z. Abidin Akasah ${ }^{1} \&$ M. Alias ${ }^{2}$ \\ ${ }^{I}$ Faculty of Civil and Environmental Engineering, Malaysia \\ ${ }^{2}$ Faculty of Technical Education, Malaysia
}

\begin{abstract}
The preservation of heritage school buildings requires special maintenance management practices. A thorough understanding of the maintenance management process is essential in ensuring effective maintenance practices can be instituted. The aim of this research was to develop a generic process model that will promote the understanding of an effective management of maintenance process for heritage school buildings. A process model for the Maintenance Management of Heritage School Buildings (MMHSB) was developed using the Integration Definition for Function Modelling $\left(\mathrm{IDEF}_{0}\right)$ system through an iterative process. The initial MMHSB process model was submitted to a team of management experts from the Malaysian Ministry of Arts and Heritage and the Ministry of Education Malaysia for verifications. Based on their feedback the initial model was refined and a proposed model was developed and sent to them for a second verification. The feedback received from the second verification formed the basis for the final model that was also validated by the same experts. The final model elucidates the items for the input, mechanism, control and output elements that are critical in the maintenance management of heritage school buildings. The model also redefines the existing scope of responsibilities of the Headmasters' and Senior Assistants' in the management of maintenance. The perceived effectiveness of the model by potential users was surveyed using a selected number of administrators from about to be recognised heritage schools. The results indicated that the process model is perceived as being helpful in clarifying the maintenance management process of heritage school buildings and is potentially useful in changing the current reactive management practices to that of a more proactive practice. In conclusion, the MMHSB Process Model is potentially helpful in promoting understanding of the maintenance management process, which would lead to improve preservation practices of heritage school buildings.
\end{abstract}

Keywords: heritage school buildings, process modelling, maintenance management system. 


\section{Introduction}

Heritage conservation in Malaysia has been considered as a new practice compared to the more developed countries in the world. Malaysia has inherited hundreds of heritage buildings; 181 buildings from the past including from the Indians, Chinese and Colonials era apart from the indigenous traditional buildings [1]. For school building, Victoria Institution (VI) which is one of the leading schools in the Klang Valley and the alma mater for some of the most influential and powerful Malaysians have been listed as the $1^{\text {st }}$ National Heritage School on the $14^{\text {th }}$ February 2009 [2]. VI was founded by Sultan Abdul Samad, William Hood Treacher, Loke Yew, Thamboosamy Pillai and Yap Kwan Seng on Aug 14, 1893. VI has played an important role in the nation's history and it is also the second English high school in Malaya after Penang Free School [2, 3].

Since the Minister of Unity, Culture, Arts and Heritage, who happens to be an old boy of VI, has declared that the school can now revert to the old English name following the awarding of the National Heritage status, it would also be appropriate for the Minister to also consider other world-renowned and historically rich schools in the country, such as Penang Free School, to be accorded similar status. However Penang Free School (built in 1816) need to follow National Heritage Acts (2005) requirements before Unity, Culture, Arts and Heritage Ministry recognised as one of the heritage school building in Malaysia. Figure 1 shows the main entrance to VI.

Whatever it is Unity, Culture, Arts and Heritage Minister called for the school's heritage to be conserved as each characteristic "be it a wall, a window, balcony, roof, tower or its field has its own story". Till today VI has maintained a record of academic excellence and produced many leaders and luminaries. Therefore VI should be prepared to maintain the status quo as before and in the future, especially related to building physical [4]. Figure 2 shows VI distinctive clock tower at the main entrance of the building.

Since VI is the first recognised heritage school in Malaysia, an overview history of the building will be explained. This explanation is very important in order to relate the process of maintaining heritage building from deteriorating. VI history will alleviate the process of maintenance to be done to preserve heritage school building for comfort during teaching and learning in the future.

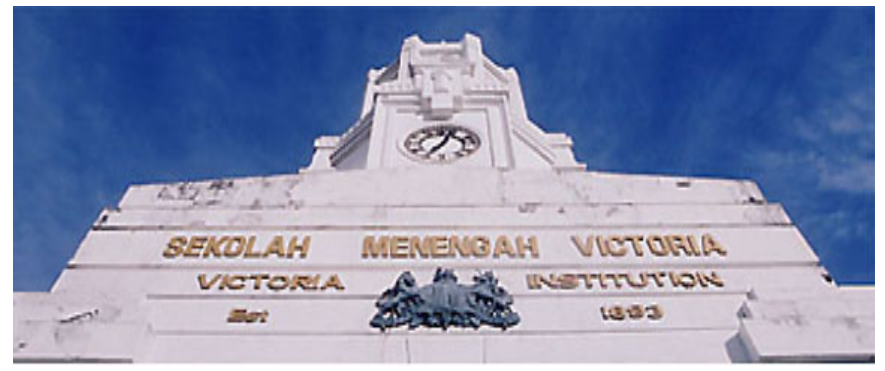

Figure 1: $\quad$ Main building entrance of Victoria Institution (VI) $[2,3]$. 


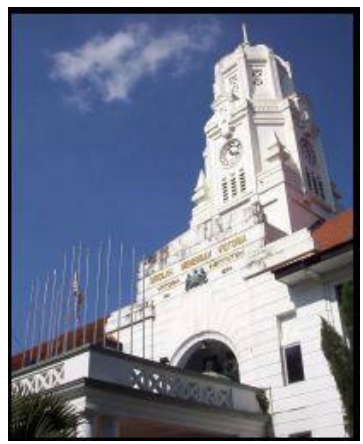

Figure 2: $\quad$ Victoria Institution's distinctive clock tower [3].

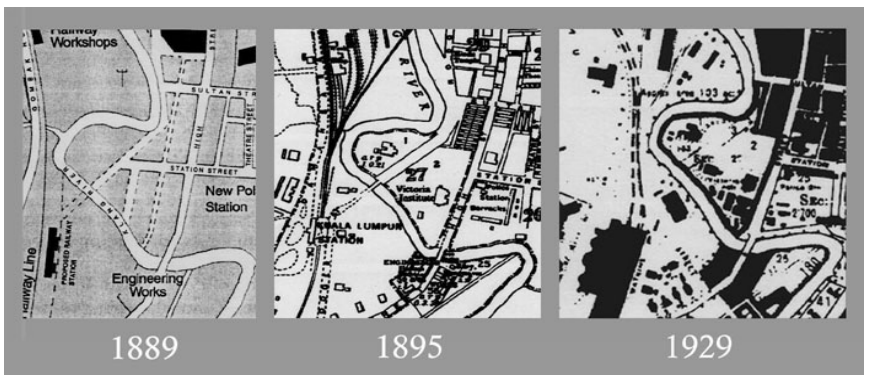

Figure 3: $\quad$ VI Building construction phase $[5,6]$.

\section{Preservation process of VI heritage building}

The present VI building dates from 1929. Before that the VI was located in High Street (now Tun H.S. Lee Road) in the heart of old Kuala Lumpur town where the school was first established in 1893. As the school grew over the decades, its environment also grew and changed, mirroring the parallel growth of Kuala Lumpur [5]. The building construction phase is shown in Figure 3.

When Malaya government approved the establishment of the VI, eight acres of land on the left bank of the Klang River were set aside. The map of 1889 in Figure 3 shows a vastly different Kuala Lumpur from that of today. Construction began in 1893 of two buildings, one a school block known as Block 1 and the other a large bungalow for the Headmaster. Block 1 had two floors, the ground floor being mainly of brick while the upper part of the building was largely timber floor. The map of 1895 shows the school a year after it opened. Block 1 fronts High Street while the Headmaster's Bungalow is further away at the bend of the river. While the map of 1929 shows a vastly changed VI All the buildings that make up the school complex are in place [5,6]. The map of 1939 in Figure 4 shows a significant change in the former VI complex. 


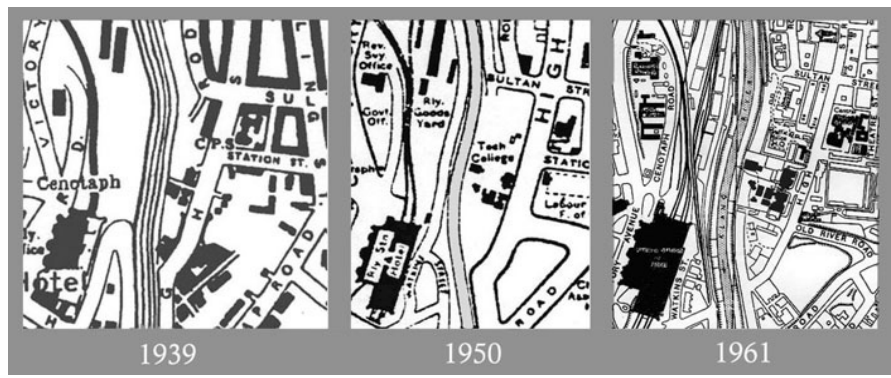

Figure 4: $\quad$ VI Building construction phase $[5,6]$.



Figure 5: Graphic visualization depicts VI in the late twenties [6].

The map of 1950 shows little change in the former VI complex five years after the World War II. Where as the map of 1961 shows a densely packed postMerdeka Kuala Lumpur, with buildings sprouting everywhere. The river has become a road [6]. Figure 5 shows a graphic visualization depicts VI at the end of a school day in the late twenties.

While across the Klang River in the background is the Railway Station and facing the school (roof partly shown on left foreground) are the barracks of the High Street Police Station [6].

\section{Fire safety maintenance process in heritage school}

It has been accepted as a fact, that as school buildings become older, more fire protection is required. Hence, more people are placed at risk from fire than before [6]. An outbreak of fire in historic buildings often has more serious consequences than it has on a modern building. This is because of the large amount of timber in the construction of the building structure, while building fabric is weak in fire resistance. Such consequences happened to VI on the evening of July 26, 1999, a fire broke out in Block 1. The roof and wooden floor were destroyed although the concrete walls survived. The gable with "1893" 


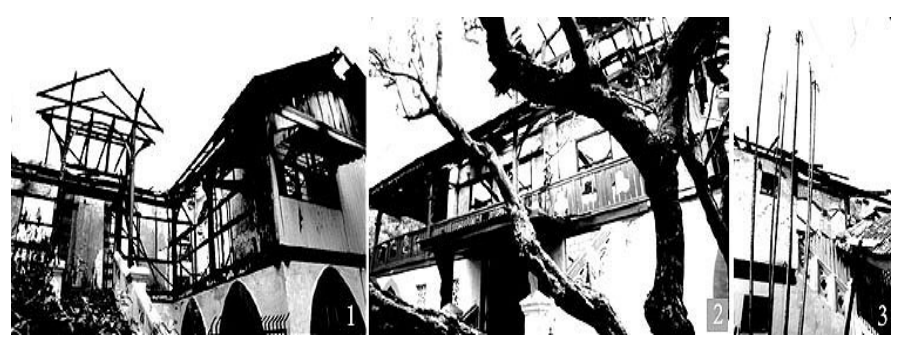

Figure 6: $\quad$ Effect of fire to Block 1 VI in 1999 [6].

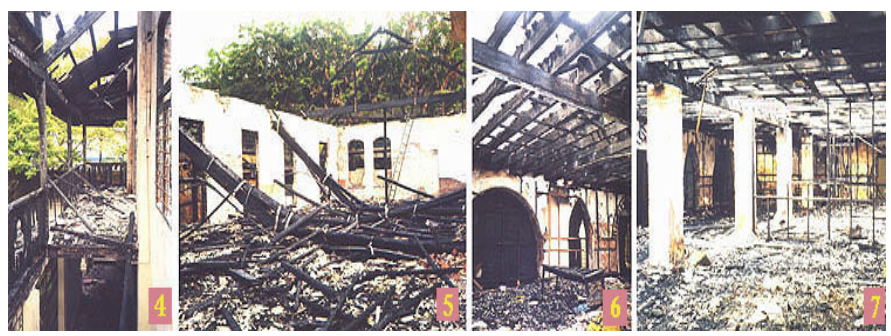

Figure 7: $\quad$ VI heritage building after fire in 1999 [6].

inscribed on it and which had stood for 106 years was consumed by the flames. Such photograph as in Figure 6 below shows the incident where no. 1 shows the skeletal remains of the porch facing High Street; no. 2 shows the southern façade with its small wooden porch and no. 3 shows the northern façade with part of the long curving porch most of which has been spared [6].

In the photograph in Figure 7, no. 4 shows the southern façade from the top of the stairs, no. 5 shows collapsed rafters on the first floor beams, no. 6 shows the ground floor with ubiquitous gothic arches in the background and no. 7 shows the ground floor with remains of partitioning that were probably of post- 1960 vintage $[7,8]$.

Heritage buildings in Malaysia are considerable of architectural and historical importance and their destruction by fire is an irreplaceable loss. It should be well kept and protected from fire danger at all time. Lessons of major fires in heritage buildings such as Victoria Institution, is that every building should have a good fire resistance to prevent fire from outbreak [6, 8]. Fire resistance is one of the ways to minimise the outbreak of fire from destroying heritage buildings. Most heritage buildings is built with fire resistance materials, which is by today's standards, fall far below the required performance with regard to Building Regulations and Fire Precautions Acts in Malaysia [7, 8].

Maintaining heritage school buildings in good condition through preventive measures make sense for academic, health as well as economic reasons [9, 10]. However, there appears to be a lack of preventive maintenance culture in general, not only in normal maintenance but also in maintenance of heritage building. One of the root causes of the problem is the lack of an understanding of the maintenance management process for heritage building among school 
administrators as such it hinder the schools from designing a good maintenance programme for their schools.

Process mapping has been identified as one of the techniques that can facilitate one's understandings of a process through a rigorous analysis of and an appropriate representation of the existing process using suitable mapping or modelling tool. Examples of process mapping tools include flow charts, Petri nets, Unified Modelling Language, the Integration Definition for Function Modelling $\left(\mathrm{IDEF}_{0}\right)$. Thus next sub-topic will discuss the development of a process model for the management of heritage school buildings using the $\mathrm{IDEF}_{0}$ modelling system.

\section{IDEF $_{0}$ modelling system in heritage school building}

IDEF is defining as the common name referring to classes of enterprise modelling languages. Whereas the objective of IDEF is to use for modelling activities necessary to support system analysis, design, improvement or integration. Besides that originally, IDEF was developed to enhance communication among people trying to understand the system. Now, IDEF is being used for documentation, understanding, design, analysis, planning, and Integration [11].

This $\mathrm{IDEF}_{0}$ generic modelling system is based on research done by Zainal Abidin Akasah (2007) for the Ministry of Education Malaysia. The same concept and framework applied for modelling heritage school buildings as due to the fact that VI management is in the same system and organisation.

In the 1970's, IDEF $_{0}$ originated in the U.S. Air Force under the Integrated Computer Aided Manufacturing(ICAM) program from a well-established graphical language, the Structured Analysis and Design Technique (SADT). The $\mathrm{IDEF}_{0}$ modelling system is a structured design and analysis technique based on graphics syntaxes and semantics [12]. This system enables a designer to produce a process model that is descriptive as well as comprehensive. In the early 1980s the U.S National Institute of Standards Technology (NIST) published the system in the Federal Information Processing Standard as a manual under the topic of Integration Definition for Function Modelling $\left(\mathrm{IDEF}_{0}\right)$. Through continuous improvements of the manual, the Institute of Electrical and Electronics Engineers (IEEE) established the $\mathrm{IDEF}_{0}$ standards (IEEE Std 1320.1-1998). Since then $\mathrm{IDEF}_{0}$ has been often used not only for process modelling but also for evaluation of current process models [13].

\section{IDEF $_{0}$ Procedures used in heritage building maintenance}

Three main stages of process modelling in the $\mathrm{IDEF}_{0}$ system, (i) constructing a context model, (A-0 model), (ii) identifying the main activity from the A-0 activity (first decomposition to obtain A0 model) and (iii) identifying subactivity of the main activities in the A0 model (second decomposition). The $\mathrm{IDEF}_{0}$ system limits the number of decomposed activity to a minimum of three and a maximum of six. Each decomposed activity is labelled with a number 


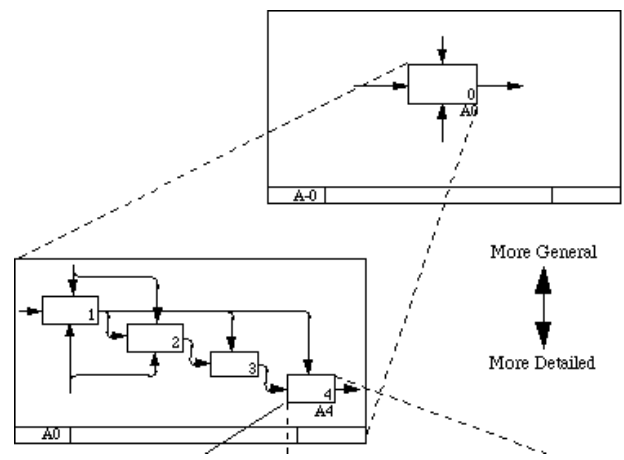

Figure 8: Decomposition of a parent activity to its sub-activities [14].

according to the label of the parent activity. An $\mathrm{IDEF}_{0}$ diagram does not contain information on timing. Figure 8, illustrates how a parent activity is decomposed into its sub-activity and links together the context diagrams [14].

\section{Development of generic heritage building maintenance management process model}

The generic heritage building maintenance management process model (HBMM Process Model) was developed in three main stages,

6.1 Stage I - gathering of information

6.2 Stage II - developing a draft process model

6.3 Stage III - verifying the process model

\subsection{Stage I - gathering of information}

Stage I, involves gathering of information on existing practices from two levels of sources, Unity, Culture, Arts and Heritage Ministry, Ministry of Education and VI management. Two information gathering techniques used were document analysis and internet browser. Documents analysed include National Heritage Acts (2005), government circulars and school maintenance research. 15 school heads for school age more than 70 years old, three education administrators and two officers from Unity, Culture, Arts and Heritage Ministry were included in the questionnaire and interview samples respectively.

\subsection{Stage II - developing the draft model}

The draft model was developed through and interactive mapping operations of existing maintenance process according to Ministry of Education. Information is mapped based on the answers to the four ICOM questions. Through the interactive process, the context model (A-0) was first produced, followed by the main function model (A0 model) and followed by the sub-function models A1, A2 and so on. 


\subsection{Stage III - verifying the process model}

The draft model was evaluated by officers from Unity, Culture, Arts and Heritage Ministry and Ministry of Education. These experts have had more than 10 years experience in the field of maintaining heritage buildings. The evaluation and verification process is an iterative one (Presley et al. [11]) starting with submission of the draft model to the experts as in Figure 9. The experts looked at all information presented in the model and marked with a tick $(\sqrt{ })$ to show their agreements and with a cross $(\mathrm{X})$ in red ink to show their disagreements with any presented information. The experts also give suggestions for improvements. The returned model is called recommended model is then refined by the author accordingly and the experts' opinion was sought for confirmation where necessary. Three types of feedback were obtained from the experts; questions on syntaxes, questions on textual information and process recommendations.

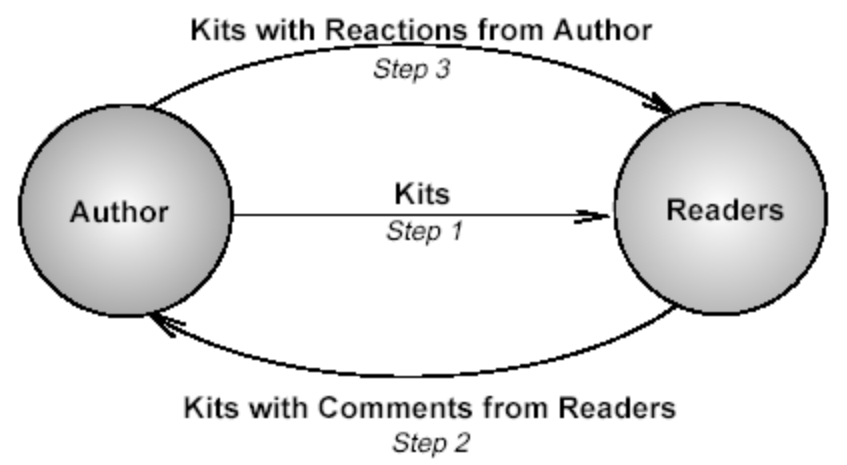

Figure 9: $\quad$ Method for verifying generic heritage process model [14].

The experts agreed that the activities, their sequence and descriptions were accurately represented. The experts also gave some suggestions on additional control elements which were incorporated into the model. The model was not submitted again as the changes were minor and verifications were obtained through phone discussion. Then this model is now recognized as a publication model; ready to be used school heads as guidance for the maintenance management of school buildings.

\subsection{Context model}

The context model was constructed based on the answers to the four ICOM questions. Based on the first ICOM question two input elements were identified,

- Building type

- Equipment/materials

Based on the second ICOM question, eight control elements were identified,

- Building layout plans,

- Inventory records/log book,

- Equipment specifications/standards, 
- Vendors,

- Types and costs of materials,

- Technical knowledge and skills,

- Budget allocations

- Associated forms.

Figure 10, illustrates the context model showing the relationship between input, control, mechanism and output. This Context model is called as A-0 Maintenance Management Heritage School Building (MMHSB) generic process model.

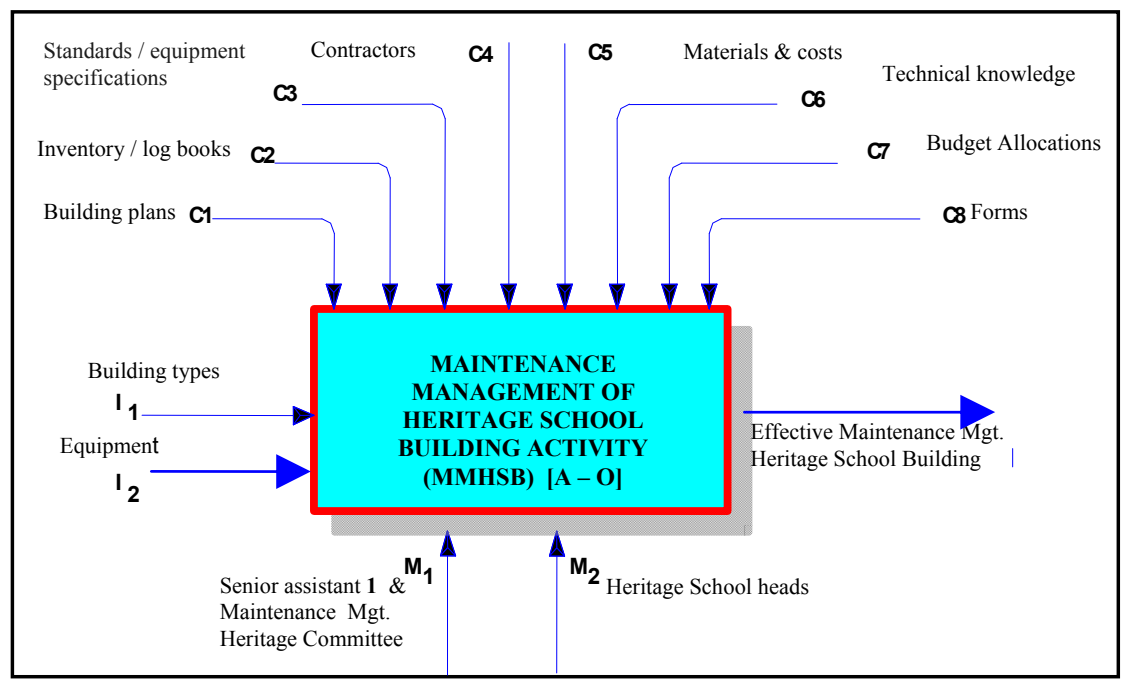

Figure 10: Level A-0: context model for the MMHSB generic process model [15].

\subsection{Main function model}

The second level in the hierarchy of the MMHSB Process Model (level A0) is the main function model. The main function model is the results of the decomposition of the context model. Similar to the previous process, the identification of the main functions and its descriptions were achieved by asking the four ICOM questions. The main functions were identified from existing practices and the A0 model was developed by integrating information on existing practices (based on the results of document analyses, responses to questionnaires and interviews) and best practices. The six activities identified for the main function model are,

(i) Determine heritage building status (A1)

(ii) Assess and evaluate defects (A2)

(iii) Estimate maintenance costs (A3)

(iv) Plan maintenance activities (A4) 


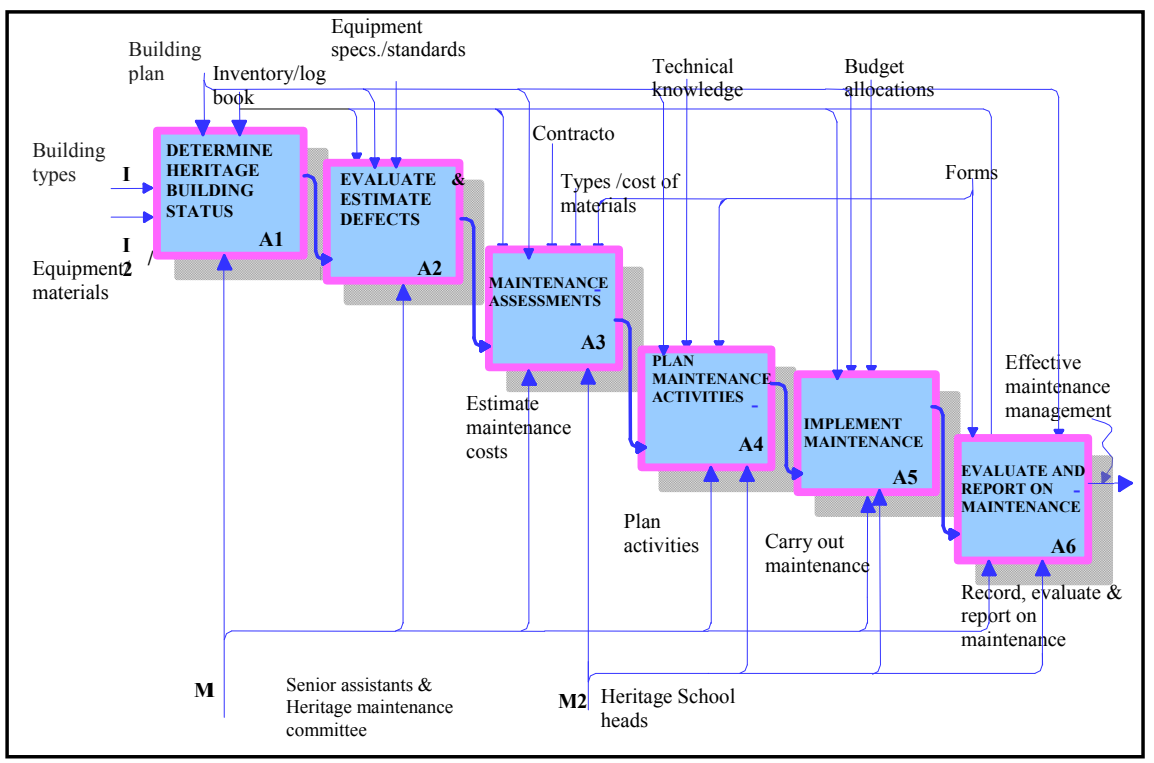

Figure 11: Level A0: Main function MMHSB generic process model [15].

(v) Implement maintenance activities (A5)

(vi) Evaluate and report maintenance (A6)

The representation of the relationships and descriptions of the six activities is called model A0 and is illustrated in Figure 11. There are a set of 18 pages of set kit MMHSB with six level including 23 activities to be used by heritage school organisation [15].

\section{Conclusions}

This article describes the development and application of a generic process model for preservation in maintenance management of heritage school buildings using the $\mathrm{IDEF}_{0}$ methodology. The development of the model involves a three stage process namely data gathering, development of a draft model and verification of the draft model. The systematic process has resulted in a process model for maintenance management of heritage school building. The resulted model is an integrated and comprehensive model that is able to clarify the process of heritage school building maintenance. The strength of the model lies in the fact that it can provide a detailed concrete evidence of the relationships between four management parameters namely maintenance heritage activities, maintenance components, human resource, and materials. Therefore, the applications of this model are expected to improve understanding of the heritage maintenance process. Even though the model has been developed based on data of heritage school building maintenance, the model is potentially adaptable for heritage maintenance of other types of buildings by modifying the four parameters, input, control, mechanism and output. 


\section{References}

[1] Kamaruzzaman, S. N.and Edwards, R. E. Living in Earthen Cities. kerpic05 ITU Istanbul, Türkiye. Paper code 11. 6-7 July 2005.

[2] The Star, Feb 14, 2009. It's back to Victoria Institution from now on. http ://thestar.com.my/news/story.asp?file=/2009/2/14/focus/3279119\&sec=foc us

[3] The Star. Feb 18, 2009. Accord Penang Free School heritage status too. http ://thestar.com.my/news/story.asp?file=/2009/2/18/focus/3279119\& $\mathrm{sec}=$ focus

[4] The Malaysian Insider, 2009. March 27, 2009. Victoria Institution becomes a National Heritage site. http://www.themalaysianinsider.com.my/ index.php/malaysia/18321-victoria-institution-becomes-a-national-heritagesite

[5] Praba Ganesan. (VI 1985 - 1991). Happy Birthday V.I.110 Years and still running the rest ragged. http://www.viweb.freehosting.net/110years.htm

[6] Chung Chee Min. The School at the River Bend. Created on 09 April 2000. Last update on 23 November 2003. http://www.viweb.freehosting.net/ viOldVI.htm

[7] DOE (Department of Environment) (1990). Standard Fire Precautions for Contractors. HMSO, London.

[8] Wahab, L.A. (2001). Fire Resistance in Historic Buildings. MSc. Dissertation, University of Portsmouth, UK.

[9] Lair, Susan Brooks (2003). A study of the effect school facility conditions have on student achievement. Unpublished PhD Theses. The University of Texas at Austin, $235 \mathrm{pg}$

[10] Sufean Hussin (2003). Educational Innovations in Secondary Schools in Malaysia .The Learning Conference 2003. What Learning Means. Institute of Education. University of London, 15-18 July 2003.

[11] Presley. A. and Waltman. W. D. (1993). Reading and Critiquing an IDEF0 Model. Enterprise Integration Frameworks Group. Automation \& Robotics Research Institute

[12] Cooper R., Kagioglou M., Aouad G., Hinks.J., Sexton.M, Sheath D. (1998). Development of a Generic Design and Construction Process. Proceedings of the European Conference on product data technology, pp 205-214, BRE, 1998

[13] IEEE Std. 1320.1-(1998). IEEE Standard for Functional Modelling Language-Syntax and Semantics for IDEF $F_{0}$. Software Engineering Standards Committee. IEEE Computer Society. USA.

[14] FIPS PUB 183 (1984). Integration definition for Function Modelling $\left(I D E F_{0}\right)$. Federal Information Processing Standards, United States National

[15] Zainal Abidin Akasah (2008). Generic Maintenance Management Process Modelling for School Building. Un-published PhD. Theses. Faculty of Built Environment. University Technology Malaysia. $280 \mathrm{pg}$. 